\title{
Is Agricultural Biotechnology Part of Sustainable Agriculture? Different Views in Switzerland and New Zealand
}

\author{
Philipp Aerni \\ University of Bern and ETH Zurich, Switzerland
}

\begin{abstract}
Most countries claim to be committed to sustainable agriculture. Yet, the meaning of the term 'sustainable agriculture' is largely shaped by influential stakeholders in the public debate and their respective agendas. The resulting national policies to promote sustainability may therefore not always be conducive to improving the economic, social, and environmental conditions of the farming sector. Two recent surveys on sustainable agriculture conducted with stakeholders in Switzerland and New Zealand highlight how such political interests and attitudes determine the role of technology in promoting sustainable agriculture. Whereas stakeholders in Switzerland largely consider precision agriculture and agricultural biotechnology to be a threat to sustainable agriculture, their counterparts in New Zealand think these factors must be essential components of the future of sustainable agriculture. The progressive attitude about sustainable agriculture in New Zealand is related to the influence of innovative food research organizations and entrepreneurial producer associations in public policy. The defensive attitude in Switzerland is largely due to the importance of government institutions, NGOs, and large retailers in particular.
\end{abstract}

Key words: sustainable agriculture, agricultural biotechnology, Switzerland, New Zealand.

private standards, in addition to the already existing restrictive public standards. But do such policies and retailer strategies really promote best practices in sustainable agriculture or do they just cater to popular anxieties among well-funded, lifestyle-oriented urban dwellers (Aerni, Rae, \& Lehmann, 2009)? Many legal experts believe in the defensive view of sustainability. They regard new technologies in agriculture implicitly as a threat to intergenerational equity and biodiversity (Bail, Falkner, \& Marquard, 2002; Francioni, 2001) and endorse the use of a strong version of the precautionary principle to protect consumers and the environment from the potential risks of genetically modified organisms (GMOs; Cooney \& Dickson, 2007; Raffensberger \& Tickner, 1999). The strong version of the precautionary principle, which is largely applied in the European Union when it comes to chemicals and GMOs, places the burden of proof on those who argue that a proposed activity will not cause significant harm, and make the responsible parties liable for environmental harm. In its Communication Paper on the Precautionary Principle, the European Commission argues that "decision makers faced with an unacceptable risk, scientific uncertainty, and public concerns have a duty to find answers" (2000). The fact that public concerns were included retailers) that claim to promote 'good agricultural prac-
tices' by asking producers to comply with burdensome 
gave many European governments sufficient reason to invoke a ban on GMOs in agriculture without having to present scientific evidence.

In all these efforts to prevent potential risks to the environment as well as human, animal, and plant health, there is also an increasing real risk arising from inaction in efforts to find solutions to current problems of sustainability (Sunstein, 2005). This is the main point raised by those who favor a more progressive view of sustainability. Such a progressive view starts from the baseline assumption that technological and economic change is necessary for society to become more sustainable because the continued use of existing, often polluting or inefficient technologies, and the ideological orientation (e.g., the continued belief in the predictability of models with a pre-defined and limited set of future outcomes) in risk management is a recipe for future environmental and economic crises (Aerni, 2009). This is especially true for agriculture where the future challenges related to climate change, food security, land degradation, biodiversity loss, and animal welfare cannot be addressed with a business-as-usual approach (Aerni, 2008; Beckerman, 2003). Deficiencies of organic agricultural practices need to by addressed by investing more in research and development (R\&D) and combining it with the modern tools of agricultural biotechnology (Ronald \& Adamchak, 2008). A progressive view does, however, not advocate a 'technological fix' but emphasizes the responsibility of policymakers to design an institutional setting that incentivizes tailormade solutions that encourage investment in R\&D, local entrepreneurship, and the use of technology as a tool of empowerment (Nordhaus \& Shellenberger, 2007; Von Hippel, 2006). Those who endorse the progressive view emphasize the fact that the use of new technologies in agriculture is not just meant to increase productivity but also helps improve food quality and environmental management (Kingsbury, 2009; Ronald \& Adamchak, 2008). In this context, they tend to be highly sceptical of agricultural subsidies that largely serve well-organized political interest groups with an interest in preserving the status quo at the expense of innovators and domestic agriculture in developing countries. Developing countries find it increasingly hard to compete with subsidized agricultural exports from affluent countries in their domestic market and are increasingly excluded from access to affluent food markets because they can't afford to comply with the burdensome private standards required by the large retailers (Paarlberg, 2008). Yet, while export subsidies are to be phased out by 2013, private standards as a tool to shut out innovative competi- tors from developing countries are likely to increase in importance, as the following section will illustrate.

\section{The Problem with Private Standards}

The framing of sustainable agriculture as an 'avoidance of risk' has been embraced most decisively by large supermarket chains (Freidberg, 2007). These globally active retailers realized that they could benefit from such a defensive view of sustainability. By forcing suppliers to undergo a lengthy and arduous audit process in order to get standard certification, they would signal to consumers that they share their values by caring about food safety, animal welfare, environmental protection, and worker welfare. The audit culture gives them a sort of moral legitimacy through rituals of verification, even though the objectives behind such a culture are not very transparent (Power, 1997). The audit culture also allows them to fend off legal liabilities more easily, force smaller and more innovative competitors to adopt their rules or leave, and improve their brand image. In their efforts to introduce an audit culture in the agricultural supply chain and set benchmarks to promote a 'greener and fairer food system' they closely collaborate with non-governmental organizations (NGOs) and food activists who see organic farming as the solution and agricultural biotechnology as the big threat to sustainable agriculture. Since most of these NGOs have a reputation of acting in the public interest and for the benefit of the planet, retailers once again benefit by presenting themselves as allies of those who care about the environment and the poor. It also decreases the likelihood of becoming a target of NGO protests against corporate power. In fact, NGOs effectively endorsed both the retailer's self-interested use of good practice codes and the broader post-'Washington consensus' faith in corporate social responsibility as a force for development and poverty reduction (Dolan, 2004; Vives, 2001). As such, retailers and NGOs contributed to the increasing substitution of practical knowledge and experience for codified epistemic knowledge that is supposed to be applicable everywhere and anytime. This epistemic knowledge has its roots once again in the European conviction of the superiority of its knowledge and applications (Drayton, 2000). The export of its 'superior' standards and regulations into other parts of the world through its 'global partnership for safe and sustainable agriculture' (EurepGAP has become GLOBALGAP) is therefore portrayed not just as a blessing to other countries but a moral right (Campbell, 2005). In this sense, the current conquest of standard practices in agricultural 
and environmental management pushed by retailers and NGOs strongly resembles earlier exports of imperial European ideology (Freidberg, 2007).

\section{Switzerland and New Zealand: Two Countries with Different Approaches to Sustainable Agriculture}

Even though Switzerland was never a colonial power, its retail industry, civil society, and government have fully embraced the European concept of multifunctional agriculture and the audit culture associated with it to ensure agricultural sustainability. These stakeholders are also actively exporting this defensive approach to developing countries by promoting 'good agricultural practices' (meaning GMO-free, organic agriculture) via foreign aid projects as well as the compliance with public and private food and environmental standards required to get market access and foreign aid (Aerni \& Bernauer, 2006). The strategy of Swiss stakeholders may be driven by a feeling of moral superiority but also by the fact that Swiss farmers are still heavily dependent on government support (mainly via various kinds of conditional direct payments), and therefore non-tariff trade-barriers have been erected in order to shield them from foreign competition (Häberli, 2008). The legitimacy of promoting and financing multifunctional agriculture in Switzerland is largely derived from the agricultural article (Article 104) in the Swiss constitution. This article was approved by the Swiss people in a national referendum in 1996. It states that the government must ensure a market-based but sustainable agricultural sector that also takes into account the need for the conservation of natural resources and decentralized settlement. It is based on the assumption that farming provides public services that are not remunerated by the market and therefore justify government intervention.

Partly in response to the new policy, Swiss agriculture has become less intensive compared to the early 1990s. The adoption of integrated management practices (IP) increased from $10 \%$ in 1990 to $100 \%$ in 2000 and organic farming from $2 \%$ to around $12 \%$ of all Swiss farms. In the same period, the surface of ecological restoration area (ökologische Ausgleichsflächen) increased from roughly 20,000 hectares to more than 110,000 hectares (Bundesamt für Landwirtschaft [BLW], 2007). Yet, over the past four years all the adoption curves have flattened, indicating that a ceiling may be reached in the willingness of Swiss farmers to adopt such practices.
As for chemical input, significant reductions have been achieved thanks to the use of more efficient means of plant protection. (Schweizerischer Bundesrat [Swiss Federal Council], 2006). In turn, the goals to reduce the use of nitrogen fertilizer, energy intensity, and greenhouse gas emissions have not been achieved (Binswanger \& Jochen, 2005; BLW, 2007).

'Agricultural Policy 2011,' as the new government planning period is called, continues to be dedicated to the paradigm that structural change is inevitable but must be socially acceptable. Even though Agricultural Policy 2011 contains a lot of reforms that will eventually lead to more market orientation in agriculture, the problematic past experiences with the multifunctionality approach are not addressed. Experience shows, for example, that structural change has slowed down quite a bit because direct payments increase the value of agricultural land (and therefore make inefficient farmers more reluctant to sell or lease land to more efficient ones), indirectly raise agricultural input and food consumer prices, and discourage farmers to focus on innovation and entrepreneurship (NZZ Online, 2009; Rentsch, 2006). Moreover, the state of biodiversity has further deteriorated in Switzerland in spite of all the measures put in place by the government (Koordinationsstelle Biodiversitäts-Monitoring [Biodiversity Monitoring Coordination Unit], 2009).

Furthermore, Agricultural Policy 2011 hardly addresses the question of how the national agricultural research institutes (Agroscope) could play an enabling role in supporting farmers to become more competitive and innovative. The budget for R\&D in agriculture was reduced significantly over the past decade and the research priorities shifted from production-related research to agro-ecological research. This shift was also accompanied by a stronger focus of the Agroscope Institutes on monitoring at the expense of active participation in the R\&D of agricultural goods and technologies in collaboration with farmers and the local private sector. The low priority given to agricultural $\mathrm{R} \& \mathrm{D}$ is also reflected in the rejection of the use of GM crops in Swiss agriculture. In 2005, the Swiss voted in a national referendum in favor of a 5-year moratorium on the use of genetic engineering in agriculture. In 2009, the federal council proposed to roll over the ban for another three years in view of ongoing public scepticism. The political preferences of the Swiss people as expressed in their vote in favor of the agricultural article in the constitution in 1996 and the temporary ban on GMOs in Swiss agriculture in 2005 is also a success for the stakeholders that shaped this public view of sustainable agri- 
culture. After succeeding at home, domestic stakeholders such as retailers, NGOs, and the Swiss agency for development and cooperation (SDC) felt encouraged to export this defensive attitude towards agriculture to poor developing countries with completely different conditions. Such activities could then be marketed back home as a contribution to fairer and greener food system (Aerni \& Bernauer, 2006).

Overall, this top-down approach to sustainable agriculture as practiced in Europe in general and Switzerland in particular may not be conducive to addressing the long-term sustainability problems, especially in poor developing countries where the problems result from lack of access to new technology rather than the potentially risky use of new technologies. Rather than preserving existing agricultural practices, many of these countries desperately need change fuelled by technological innovation and local entrepreneurship, the two foundations of endogenous rural development (Romer, 1994).

An important question is whether there is any alternative to the rather patronizing European view of sustainable agriculture that could serve as a flexible template for promoting home-grown development, rural empowerment and sustainable agriculture alike? New Zealand may be a candidate in view of its bold unilateral liberalization experiment in the 1980s and its subsequent focus on assisting farmers in coping with the process of globalization through public private partnerships. Its policy approach largely reflects a progressive view of agricultural sustainability. It sees economic and technological change as an opportunity rather than a problem in making agriculture more sustainable.

As a consequence of the major agricultural reforms in the 1980s, government assistance in New Zealand is today limited to support for research, pest and disease control, agri-environmental measures, and climatic disaster relief. Its reforms also caused a shift in the focus on agriculture from commodity to added value business and from a 'command and control' policy approach to a more bottom-up and incentive-based approach. At the same time, the national Crown Research Institutes were semi-privatized and encouraged to collaborate with farmers and the private sector to address the challenges of environmental sustainability and develop new agricultural products. This collaboration is increasingly contributing to a modern agricultural economy that is concerned with the constant improvement of production methods and the generation of high quality food prod- ucts. At the same time, it encourages a more sustainable use of natural resources.

In spite of the radical reforms in the 1980s, the number of rural land holdings in New Zealand remained more or less constant at around 80,000 (approximately half are commercial farms and half are 'lifestyle blocks;' Ministry of Agriculture and Forestry [MAF], 2003). By contrast, Switzerland today still has roughly 63,000 farms (excluding the 'life style blocks' or hobby farms; BLW, 2007).

After the abolishment of subsidies in New Zealand in the 1980s the decision-making power moved from government to farmers. About 300 farms were not able to cope with all the new business risks and the growing uncertainty. They decided to move out of agriculture and accept an early retirement package. One major reason for this low number of exits was the resourcefulness and endurance of the farmers themselves (N. Fraser, April 10, 2006, personal communication). It was actually the Federated Farmers (the largest farmer organization in New Zealand) that pushed for the tough reforms and assisted farmers in becoming innovative and creative entrepreneurs. In addition to that, the banks cooperated in the restructuring of farm debts while the government assumed the role of a coach for those who wanted to stay in business. Even though there was hardship, none of the farmers (and even environmentalists) would want to return to a system that heavily relies on government intervention (J. Sinner, April 11, 2006, personal communication). Moreover, the resulting creative rural entrepreneurialism improved and diversified rural economic activities, created more employment, improved food quality and choice, and made the countryside of New Zealand a more attractive place to live than ever before (Chamberlin, 1996). Ironically, the amount of land dedicated to agriculture decreased in New Zealand over the past decade (with the exception of horticulture and exotic timber cultivation), while the farm land in Switzerland slightly increased over the same period of time.

The reforms in New Zealand also led to more differentiation of the farm work. Farms are often run as equity partnerships with investors from the cities. Farmers themselves often specialize on the strategic management of the farm, while certain tasks are performed by professionals from outside (milking, harvesting, marketing, etc). Farm decisions depend on market prospects, the particular environmental conditions, and the regional price of labor and land (attractive tourist areas raise the opportunity costs of labor and the value of land). Farmers are also contributing to innovation in farm manage- 
ment and the development of new products. It often happens that farmers come up with a new technique or product and approach one of the universities or Crown Research Institutes to find out about its potential value and ways to improve it to a stage that makes it attractive for commercialization. In this context, farmers and researchers in New Zealand have become partners in a national enterprise (J. Luo, April 6, 2006, personal communication).

At the same time, New Zealand is equally committed to the goals of sustainable agriculture and its government is anxious to preserve the country's image of being 'clean and green. ${ }^{1}$ However, it tries to achieve sustainability in a different way. Rather than following the conventional social planning approach of multifunctional agriculture, the New Zealand government sees itself as a facilitator of sustainable change through the promotion of technological innovation and rural entrepreneurship, strict biosecurity control, as well as incentives to adopt sustainable farming practices. The Resource Management Act (RMA), passed in 1991, pursues a decentralized bottom-up approach in environmental policy. The New Zealand government is authorized to issue national environmental standards, but it is up to the regional authorities (Regional Councils) to choose the best approach on how to implement them. There is a growing concern that this decentralized approach is too slow in view of the rapidly increasing environmental problems (Parliamentary Commissioner of the Environment [PCE], 2004). New Zealand, however, cannot afford to promote sustainable agriculture at the expense of agricultural competitiveness, but must reconcile these two pillars of its agricultural economy by investing in innovation and best practices. The greatest share of government support therefore goes into the promotion of applied agricultural research and development through the Foundation for Research, Science, and Technology (FRST). The innovation focus of the Foundation also signalled to universities and the Crown Research Institutes that they must show how their research contributes to a sustainable and innovation-driven economy. This has led to lots of public-private research projects that have resulted in new products that benefit the environment. For example, Lincoln University and the fertilizer company Ravensdown have developed a nitrification inhibitor (eco-n) for cows that reduces nitrate leaching

1. Overall, New Zealand agriculture is still more extensive than Swiss agriculture even though sustainability problems are on the rise, especially in the business of dairy farming. (resulting from cow urine patches) into the groundwater and leads to an emission reduction of the greenhouse gas nitrous oxide. Another example is a Rapid Pasture Meter/Sensor, a product jointly developed by the Centre for Precision Agriculture at Massey University and the company C-Dax. The technology helps farmers to optimize fertilizer and water application in livestock farming (I. Yule, April 5, 2006, personal communication). Apart from these cases, numerous joint ventures between public and private research laboratories are dedicated to use the new tools of agricultural biotechnology to develop more sustainable and profitable new products, including genetically engineered crops. As an export-oriented agricultural economy that is concerned about the demand in its high value markets in Europe, however, New Zealand has not officially approved any GM food for human consumption, nor GM crops for cultivation on a commercial scale.

The focus on creating value has not just triggered entrepreneurial activity in the research centers that focus on precision agriculture and biotechnology, but also on those that are dedicated to ecological agriculture. Unlike in Switzerland, where it is implicitly assumed that traditional agro-environmental measures will contribute to biodiversity, New Zealand researchers are actively searching for plants that have a proven record to enliven biodiversity. For example, the bio-protection and ecology division at Lincoln University is adding value to its discovery of plants (e.g., buckwheat, tansy leaf) that attract beneficial insects (e.g., providing nectars for bees and enhancing biological control of wine pests) by collaborating with wine farms that would like to add an eco-friendly label to their brand of wine (growing these colorful plants between the vine rows). The approach is called ecological engineering and differs largely from the classic forms of ecological pest management. If biodiversity and ecosystem services would get a higher value (e.g., by taxing agriculture without a contribution to these services), such activities could become a real business (S. Wratten, April 12, 2006, personal communication). Like Switzerland, the New Zealand government also funds large national research projects that mainly monitor the environmental impacts of agriculture and issue political recommendations (e.g., ARGOS Project, Sustainable Land Use Research Initiative, Sustainable Development Programme of Action; T. Braisden, April 3, 2006, personal communication). The Sustainable Farming Fund of the Ministry of Agriculture and Forestry (MAF) plays an important role in the funding of these projects. 


\section{Why Conduct Stakeholder Perception Surveys on Sustainable Agriculture?}

Switzerland and New Zealand are both democracies with vibrant public debates on sustainable agriculture. As a consequence, official definitions of sustainable agriculture are highly influenced by the public attitude towards farming. Yet, who is 'the public' and what contributes to the formation of a 'public attitude'? Often, people do not have the time to form an autonomous opinion about political issues that are unrelated to their immediate concerns in daily life. They therefore tend to merely adopt the views of stakeholders that are believed to represent the public interest (Aerni \& Bernauer, 2006). Yet, no matter how civic-minded these stakeholders present themselves in public, they always try to define the public interest in a way that also serves their own interest (Sjöberg, 2003). In this sense, there is no such thing as 'the public interest' in a strict sense, but merely political actors who claim to represent the public interest (Buchanan \& Tullock, 1962). The mass media provides these actors with the necessary public stage that allows them to 'socially amplify' their views and concerns (Kasperson et al., 1988; Luhmann, 1993).

Stakeholder perception surveys are a very useful tool to understand public opinion formation from an endogenous point of view. This is based on the assumption that the views and interests of relevant stakeholders involved in a particular public debate respond as well as influence public perception. This again enables them to shape the meaning of the term 'public interest,' and, eventually, the respective policy outcomes.

\section{Stakeholder Perception Surveys in Switzerland and New Zealand}

We conducted two stakeholder perception surveys on sustainable agriculture in New Zealand (from April to August 2006) and Switzerland (from November 2006 to February 2007).

In both countries, the most important stakeholders were selected by means of key informants who were familiar with the national debate on sustainable agriculture and its participants. This method of stakeholder selection was adopted from policy network analysis (Laumann \& Knoke, 1987).

The major results of the two surveys have been published in the journals Ecological Economics (Aerni, 2009) and Food Policy (Aerni et al., 2009). This article focuses mainly on the results that look at the stakeholder assessments of the role of agricultural biotechnology in sustainable agriculture and the policy networks that

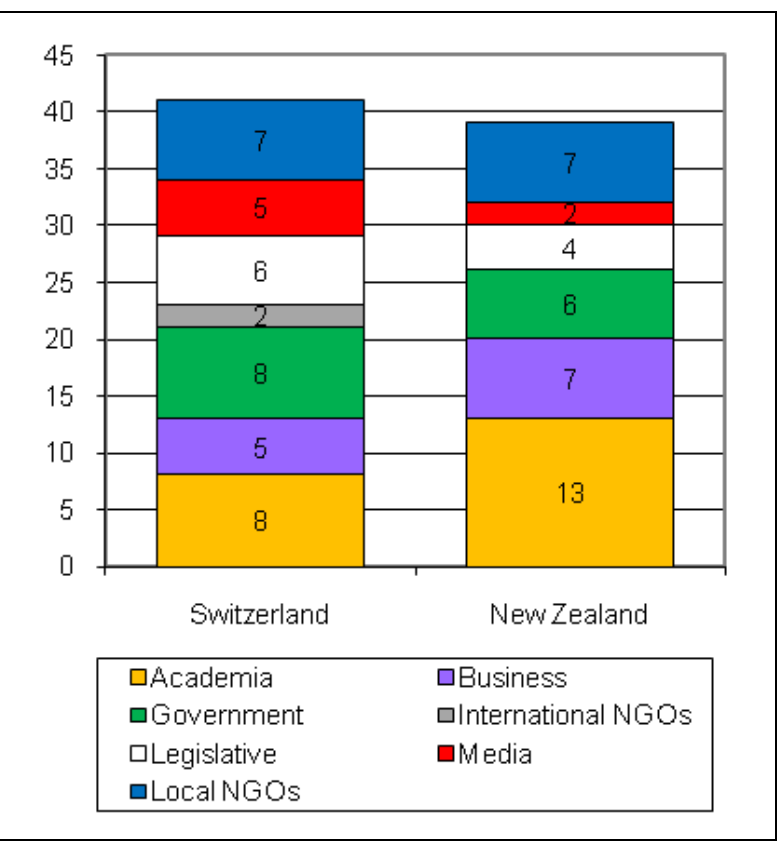

Figure 1. Number of participants and shares of the different stakeholder groups.

shape the debate on sustainable agriculture in Switzerland and New Zealand. The stakeholder attitudes toward agricultural biotechnology also reveal the perceived compatibility of agricultural sustainability and new technologies in each country.

\section{Survey Participants and Return Rates}

In New Zealand, 39 respondents completed and returned the questionnaires, which equated to an $81 \%$ return rate. ${ }^{2}$ The respondents represented 33 different domestic institutions. In Switzerland, 41 questionnaires were completed and returned (a total return rate of 86\%), representing 36 different domestic institutions.

Figure 1 shows the distribution of stakeholders in Switzerland and New Zealand. There is a higher share of representatives from academia and business in New Zealand. In turn, there were more participants from government and the legislature in the Swiss survey. This reflects the overall weight and importance of these institutions in the national public debates. Furthermore,

2. In cases where the selected stakeholder representatives felt unable to participate in the survey, we asked them to identify a proxy within their institution to replace them. The return rate takes into account the representatives that did not participate themselves but found a substitute that was willing to replace them. 
Table 1. The assessed importance of the problems in $\mathrm{CH}$ and NZ agriculture.

\begin{tabular}{lcc}
\hline & NZ & CH \\
Water & 3.641 & 2.37 \\
Nitrogen & 3.628 & 3.00 \\
Nutrients & 3.469 & 3.00 \\
Greenhouse & 3.192 & 2.90 \\
R\&D & 3.123 & 2.43 \\
Energy & 3.051 & 3.10 \\
Trade & 2.995 & 3.41 \\
Biodiversity & 2.841 & 2.98 \\
Protection & 2.8 & 2.90 \\
Incentives & 2.622 & 3.25 \\
Price & 2.533 & 2.75 \\
Support & 2.521 & 1.98 \\
Change & 2.436 & 2.88 \\
Innovation & 2.338 & 2.63 \\
Tilling & 2.328 & 2.71 \\
Monoculture & 2.2 & 2.24 \\
Quality & 2.2 & 2.10 \\
Debts & 2.119 & 2.50 \\
Culture & 2.013 & 2.20 \\
Tradition & 1.763 & 2.02 \\
\hline
\end{tabular}

respondents had the opportunity to object to the selection of relevant stakeholders listed in the questionnaire either by adding stakeholders that are missing, or after the survey, when workshops in Bern (September 2007) and Wellington (October 2007) were held with the survey participants to discuss the outcome of the study. Overall, the feedback was positive and there were no objections neither to the prior selection nor to the actual participation of stakeholders.

\section{Survey Results}

The perception analyses of the questionnaire data consisted of a descriptive analysis and a perception pattern analysis in each country.

\section{Descriptive Analysis}

In Part 1.1 of the questionnaire, respondents in NZ and Switzerland $(\mathrm{CH})$ were asked to rate the importance of 20 problems of sustainable agriculture on a scale from 1 to 4 . Table 1 presents the mean values (average ratings) and standard deviations of the assessed problems in $\mathrm{CH}$ and NZ.

It shows that 'high use of nitrogen' (nitrogen) ${ }^{3}$ and 'nutrient pollution' (nutrients) are considered to be very important problems in both countries (ranked $2^{\text {nd }}$ and

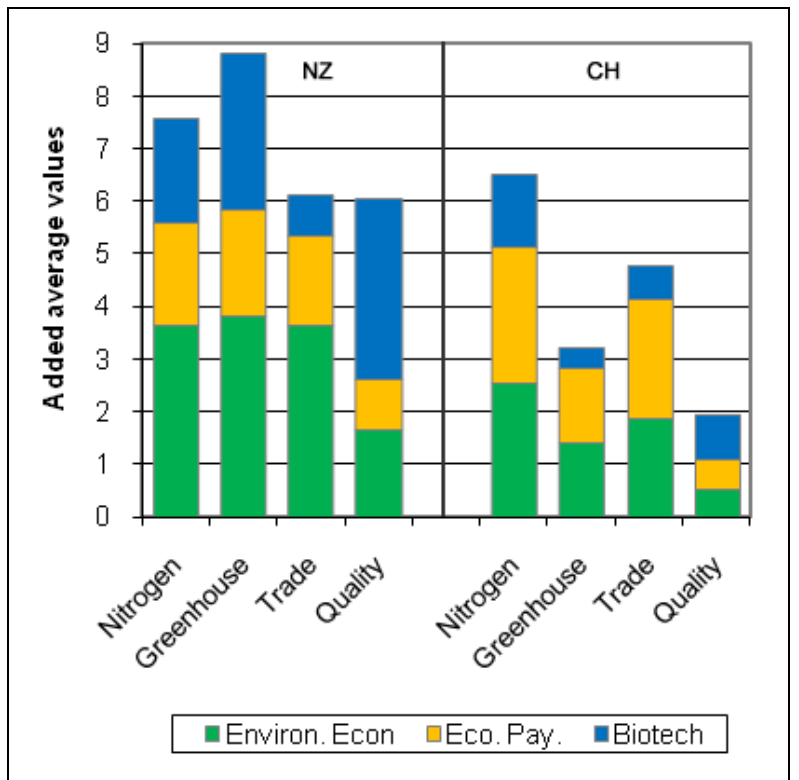

Figure 2. The appropriateness of approaches to solve selected problems in agriculture.

$3^{\text {rd }}$ in NZ and $4^{\text {th }}$ and $5^{\text {th }}$ in $\mathrm{CH}$, respectively). 'International trade competition' (trade) was ranked as the most important problem of sustainable agriculture in $\mathrm{CH}$, whereas 'high water consumption' (water) took the lead in NZ.

In Part 1.2, stakeholders were asked to assess the appropriateness of different approaches to solve each of the listed problems. The assessment of the potential of the three approaches-biotechnology (Biotech), instruments of environmental economics (Env.Econ), and ecopayments (Eco-Pay)_applied to the four problems nitrogen, greenhouse gas emissions, trade, and food quality, yielded the most interesting results for a $\mathrm{CH}-\mathrm{NZ}$ comparison.

Figure 2 shows how respondents assessed the potential of three selected approaches to solve these problems. The $y$-axis shows the sum of the average rankings ${ }^{4}$ assigned to the different approaches for each of the four problems in NZ and $\mathrm{CH}$.

The figure reveals that NZ respondents generally believed that biotechnology can make an important con-

3. Words written in Italic represent the abbreviation of a problem/statement/variable in the respective illustration.

4. The average value is based on the specific ranking. If a problem was ranked most important (number one), it received 5 points, second most important $=4$ points, third most important $=3$ points, and so on. The numbers were added up for each problem then divided by the number of participants that assessed it. 


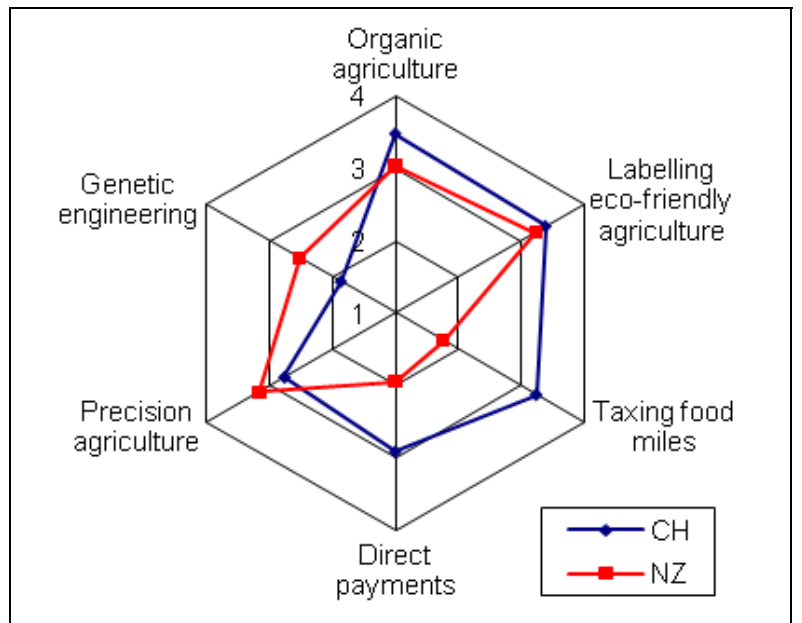

Figure 3. The assessed impact of six different practices on sustainable agriculture.

tribution to address the nitrogen problem, the greenhouse gas problem, and the problem of low food quality in particular. This is a significant observation because the role of technology in agriculture is usually associated with productivity increases rather than improvements in environmental and food quality.

In Part 1.3, respondents were asked to assess the impact of six practices (including genetic engineering) on sustainable agriculture on a scale from 1 (very negative) to 4 (very positive). Figure 3 shows the average ratings given in $\mathrm{NZ}$ and $\mathrm{CH}$ in the form of lines that intersect with concentric angular circles in a spider web.

$\mathrm{CH}$ respondents rated the impact of organic agriculture and labelling eco-friendly agriculture to be very positive for sustainable agriculture. NZ respondents do so as well but more moderately. Precision agriculture was expected to have a positive impact in both countries (but less so in $\mathrm{CH}$ ). Yet, $\mathrm{CH}$ respondents assessed the impact of genetic engineering to be very negative whereas NZ respondents expressed a more ambiguous view. This more moderate attitude towards genetic engineering in agriculture in New Zealand may be a confirmation of the hypothesis that GMOs are currently not grown in New Zealand for pragmatic rather than ideological reasons.

\section{Social Networks}

In the last part of the questionnaire, survey participants were asked to evaluate a list of stakeholders in a policy network table according to their political influence and indicate whether they are cooperating with them, and if so, in what sense (information exchange, financial support).
The data was then used to conduct a social network analysis. It allows us to identify the stakeholders in the national debates on sustainable agriculture by dint of their centrality in the different information and financial exchange networks. Social networks are increasingly popular in the analysis of political processes because they reflect a decentralized concept of social organization and government that increasingly applies to the political decision-making processes in contemporary governance structures of modern democracies (Peters \& Pierre, 2003).

In addition to the formal institutional agreements, the network perspective helps further to integrate complex informal processes into the political process. The consideration of informal processes has become more and more important since the crowded public debates and the fragmentary character of the state draws an increasingly fuzzy line between private and public (Carrington, Scott, \& Wasserman, 2005; Laumann \& Knoke, 1987).

A comprehensive evaluation of all the link-ups between the listed organizations in Switzerland and New Zealand raises serious problems. Any attempt to illustrate the total collaboration networks may result in a maze of links that lacks clarity and is difficult to interpret. Therefore, the following evaluation concentrates on different forms of collaboration, such as financial support and information delivery, and portrays them in an appropriate and simplified way.

In the policy network table, respondents were asked to specify their form of collaboration as (a) receivers of information, (b) providers of information, (c) receivers of financial support, or (d) providers of financial support.

In view of the density of the information networks, we limit ourselves to the UCINET outputs of Network B (providers of information), which shows the main providers of information in the social network and symmetrizes their respective links (symmetrization assumes that those who were marked as receivers by the providers also would have confirmed this by marking it correspondingly in Network A even though they did not take part in the survey or did not fill in this part of the questionnaire).

Figure 4 shows the information network in Switzerland derived from Network B (the providers' perspective). The network shows the institutions that receive most information from those who indicated that they give information. Core institutions in the exchange of information are NGOs such as N1-the Swiss Farmer Association (Schweizer Bauernverband)—and N4, the 


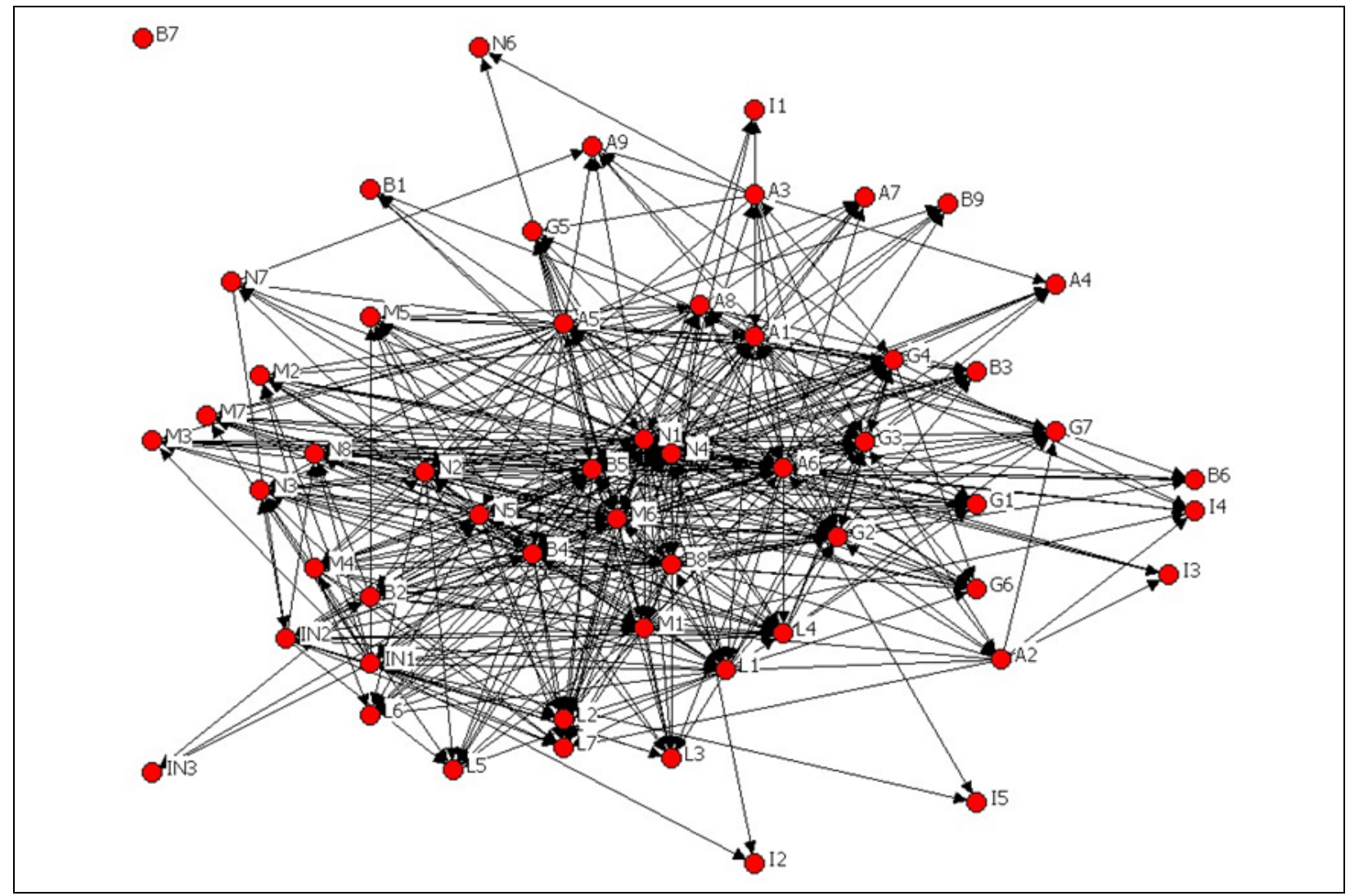

Figure 4. Swiss network of information exchange from the 'provider perspective.'

Swiss Research Institute for Organic Farming (Forschungsanstalt for Biologischen Landbau, FIBL). Moreover it contains B5-a large retailer, Migros-and M6-Swiss National Radio, Radio DRS. In the second inner circle, we find A6-an academic institution, Agricultural Research Institute (Tänikon-Reckenholz, ART) - government institutions G3 and G2-Federal Office of the Environment (BAFU) and Federal Office of Agriculture (BLW), respectively-and business B4 and B8-Coop, a large retailer, and Emmi, a large producer of dairy products, respectively. This somehow confirms the powerful influence of Swiss non-state actors (NGOs, retailers, mass media) and their strong relations to government. Academic institutions (Agricultural research institutes, universities) in turn seem to play a more marginal role (apart from A6).

In New Zealand, the maze is a little bit less dense. The network of information providers reveals that the Parliamentary Commissioner of the Environment (L1), a legislative institution, plays the most central role in Network B as the main receiver and provider of information (see Figure 5).
Apart from this stakeholder, the Labor Party (L2), Agriquality (B11) and BioGro (B12; both involved in the organic farming certification business), Rabobank (B7), Fonterra (B1; a large dairy company), AgResearch (A7; a Crown Research Institute), Lincoln University (A2), and Farmer's weekly (M3; a weekly magazine) are seen as central actors in the distribution of information. The most important government institutions in the information network are the Regional Councils (G6) and the Foundation for Research, Science, and Technology (FRST; G4), which is part of the Ministry of Research, Science, and Technology (MORST). A central provider of information seems to be Dairy Insight (N9), an independent farmer-owned organization responsible for making investments into dairy industry research, development, extension, and education projects and activities. Moreover, two NGOs - the Federated Farmers (N1) as well as Fish \& Game New Zealand (N6) - seem to also play important roles as providers of information. It is conspicuous that government institutions play a far less prominent role in the information network than in Switzerland. 


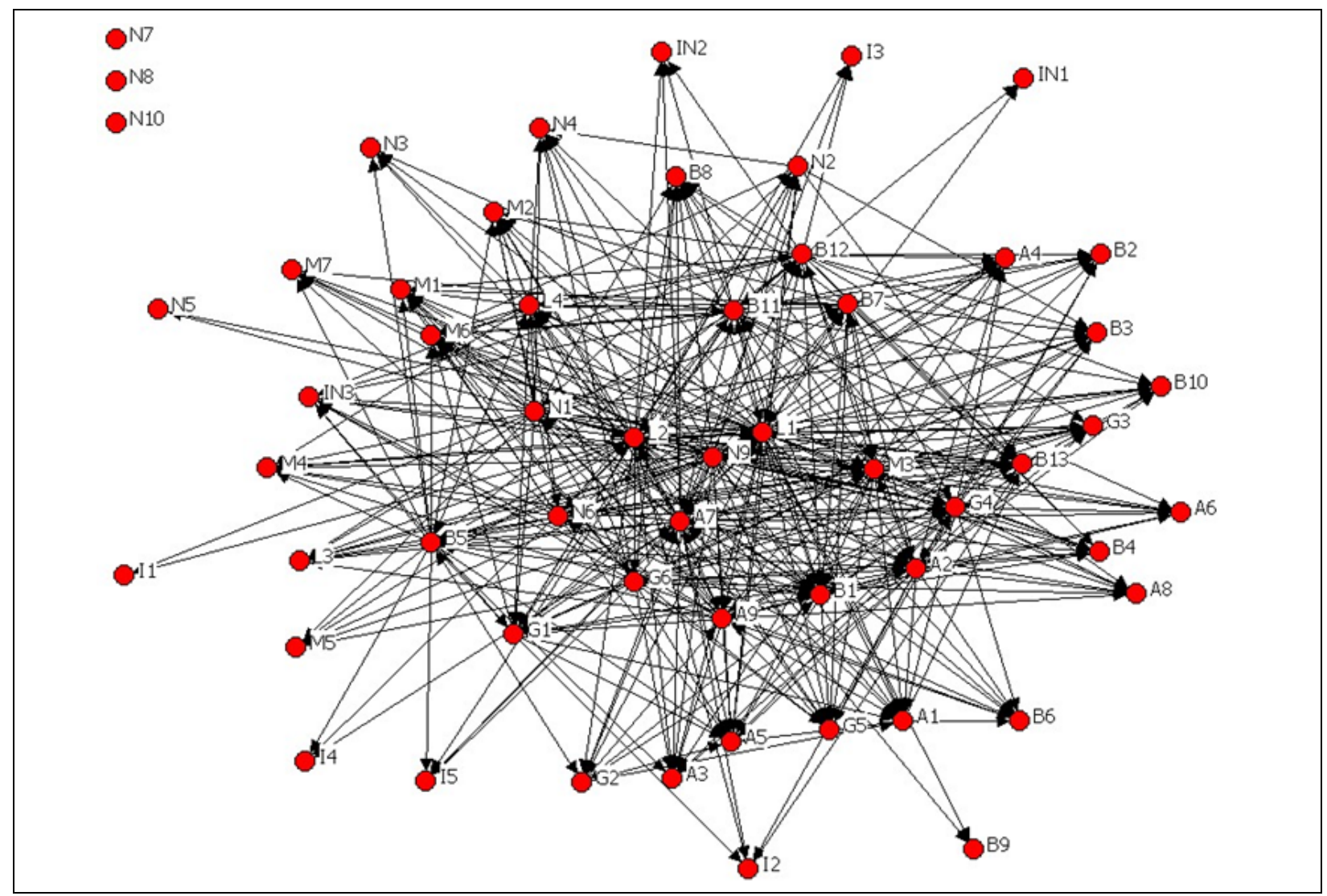

Figure 5. The NZ network of information exchange from the 'provider perspective.'

\section{Financial Networks in Switzerland and New Zealand}

Fewer respondents replied to the question whether they provide and/or receive financial support from the respective institution in the policy network table. This has advantages because there is more clarity about the exact linkages. Yet, the program UCINET which calculates Network C (receive) and Network D (provide) is unable to merge networks. Since it makes more sense to pack the relatively sparse information into one network per country, the merging of networks was carried out manually by combining the asymmetric ties of each network. This also allows the use of colors to highlight the core actors and their function in the network.

Figure 6 shows the financial support network in Switzerland. The most important providers of financial support (marked in blue) appear to be government institutions related to environment (BAFU, G3) and agriculture (BLW, G2), followed by the European Union (I4), Coop (a retailer, B4), and the Social-Democratic Party (L7). The politician of the Social-Democratic Party who filled in this part is also chairman of an NGO. This may explain the financial support given by the Party to two international NGOs.

B2 (the organic farming company 'Biosuisse') receives financial support from Coop (B4) and gives support to the organic farming research institute (FIBL, N4). FIBL also seems to be the most important receiver of financial support, followed by national and cantonal academic institutions such as the Agricultural Technical University in Zollikofen (A8), the Institute of Geography at the University of Bern (A3), ETH Zürich (Department of Agriculture and Food Science) (A1), and ART (A6; a national research institute). It is interesting to observe that only supermarket chains (B4 and B5) seem to be important business sponsors of research in agriculture and they tend to focus on supporting organic farming research. Even agro-chemical companies such as Syngenta (B1) tend to sponsor merely environmental research (A2; Institute of Environmental Sciences, University of Zurich) and support businessrelated media coverage (M4, Schweizer Bauer, der Landfreund). The State Secretariat for Research and Education (G5) seems to play a rather marginal role as a supporter of agricultural research compared to other 


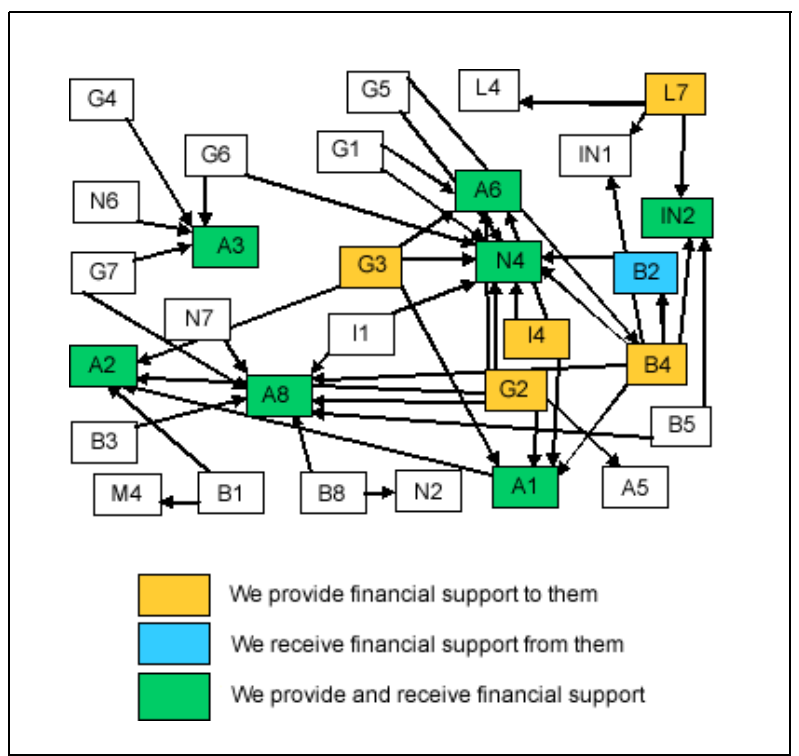

Figure 6. The Swiss network of financial support.

government institutes such as G2, the Swiss Federal Office for Agriculture (BLW), and G3, the Swiss Federal Office for the Environment (BAFU).

The network of financial support in New Zealand (Figure 7) looks slightly more dense and very different in the distribution of colors. There seem to be many more institutions that give and receive financial support. Apart from the Federated Farmers (N1), Fonterra (B1), Ravensdown (B8; a fertilizer company), and BioGro (B11), the Crown Research Institutes such as AgResearch (A7), Landcare (A5) and, to some extent, HortReserach (A8) and the Royal Society (A9) seem to play a dominant role in the giving and receiving networks of financial support. This can be explained by the fact that these national research institutes were semiprivatized in the 1990s and were therefore forced to collaborate with the private sector and compete harder for research grants. By far the most important provider of financial support is the Foundation for Research, Science, and Technology (G4). It supports research at the Crown Research Institutes and universities, as well as research conducted in the private sector (B1). Research sponsored by the Ministry of Agriculture and Forestry (MAF; G1) and the Ministry for the Environment (MFE; G2) seems to be marginal in comparison. Another important provider of financial support seems to be the ruling Labor Party (L2) that sponsors government agencies as well as research. However, the politician who filled in this part also used to be the head of the MAF. This helps explain the apparent generosity of the Labor Party. Finally, there is Dairy Insight (N9),

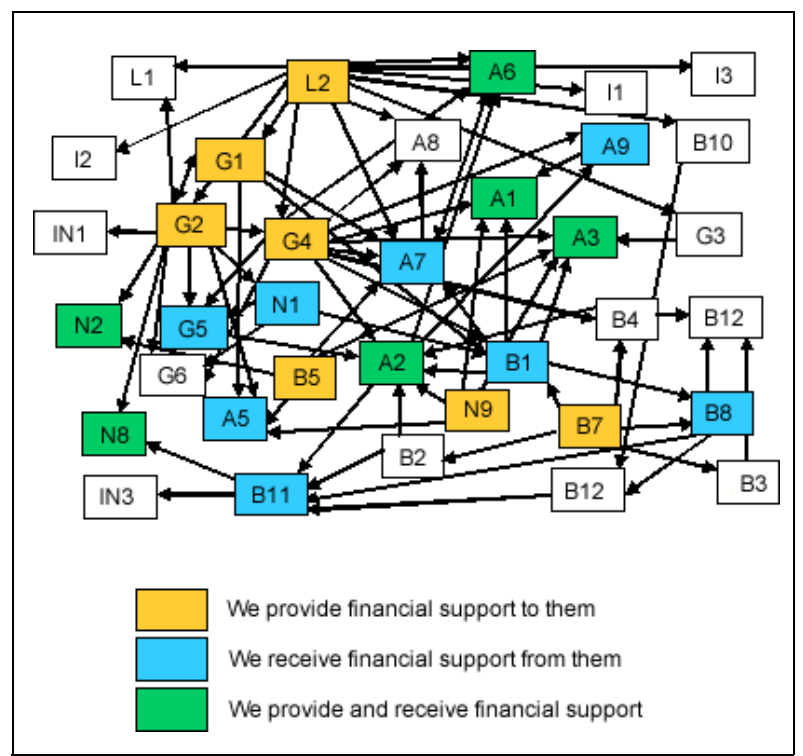

Figure 7. The New Zealand network of financial support.

which sponsors research in different academic institutions. The New Zealand Business Council for Sustainable Development and Rabobank are important sponsors in the private sector (Rabobank mainly invests in companies). Unlike the Crown Research Institutes that play a role as receivers and providers of information, universities are the main receivers of financial support, together with some environmental NGOs (Ecologic Foundation [N2] and Sustainability Council of New Zealand [N8]).

Overall, the social networks reveal that research institutes play a more dominant role in New Zealand than in Switzerland. While organic farming institutions play an important role in both networks, they are more at the core of information exchange and financial support for sustainable agriculture in Switzerland. While business closely collaborates with research institutes in New Zealand in finding solutions to problems with sustainable agriculture, this collaboration is less established in Switzerland. Swiss business stakeholders are mostly represented by retailers and they tend to sponsor advocacy groups rather than research institutes. The biggest difference between the two countries is the central role of research through FRST in New Zealand. It plays a core role as a distributor of information and is the main sponsor of agricultural research (by comparison, the Swiss State Secretariat for Research and Education is not represented in the Swiss social networks). The mission of the FRST is to convert knowledge into useful products and services for a sustainable and competitive agricultural sector. In Switzerland, the Federal Office 
for Agriculture (BLW) and the Federal Office for the Environment (BAFU) have largely assumed this role.

\section{Discussion and Conclusions}

The results of the stakeholder perception surveys in Switzerland and New Zealand confirm the assumption that the definition of sustainable agriculture largely mirrors the attitude and interests of the influential domestic stakeholders in each country. The dominant stakeholders in Switzerland are the Swiss farmer association, government institutions concerned with agriculture and the environment, NGOs committed to the promotion of organic farming, and large retailers who seek to gain an image as advocates of sustainability by banning GM food from their shelves and aggressively promoting organic products. All these stakeholders share a defensive view of sustainable agriculture, considering technological change as a threat to sustainable agriculture rather than an opportunity. In particular, they do not see any potential for biotechnology to help address the problems of sustainable agriculture. The social network confirms the influential role of large retailers as the most important actors in the food chain in Europe and increasingly also in other parts of the world. They seem to be central in the information network as well as in the network of financial support in Switzerland, which seems to be in line with their role as gatekeepers of the food chain (Fold \& Pritchard, 2005). The large retailers are also the most prominent sponsors of advocacy groups for agricultural sustainability.

Furthermore, government institutions also play a major role in sponsoring research at academic institutes. However, this research is largely focused on external expertise and agricultural and environmental monitoring work rather than concrete product development.

The situation looks very different in New Zealand. This country also regards organic farming as an important, but not sufficient, contribution to sustainable agriculture and emphasizes the importance of precision agriculture and biotechnology in efforts to make New Zealand more competitive and more sustainable. They generally reject the popular agricultural policy tools that are supposed to promote sustainability in Switzerland, such as direct payments and taxing food miles. Whereas Swiss stakeholders regard international agricultural trade as the most important threat to sustainable agriculture, New Zealand stakeholders believe that economic and technological change is necessary to become sustainable. This more progressive view is also reflected in the influence of the different stakeholders in the social network analysis. Research institutes are more at the center of the information network and they receive generous financial support from the public and the private sector, not for doing mere monitoring of the agricultural sector (as is the case in Switzerland) but for changing it through the development of new knowledge, services, and goods that help farmers cope with the economic and environmental challenges. It is therefore not surprising that the core public actor in the network of financial support is the FRST rather than the Ministry of Agriculture or the Ministry of the Environment, as it is the case in Switzerland. Interestingly, large retailers do not appear to play a significant role in the social networks of sustainable agriculture in New Zealand.

The greater focus on change and innovation in New Zealand largely reflects the belief in a bottom-up approach and the creativity of entrepreneurial farmers and researchers to find new solutions to important sustainability problems. Yet, this New Zealand approach is somewhat difficult to reconcile with the general normative view of sustainable agriculture.

Sustainable agriculture rests on the general principle that the needs of the present generation must be met in a way that does not compromise the ability of future generations to meet their own needs. This basic definition of sustainability became generally accepted after the highly influential Brundtland Report entitled Our Common Future (Brundtland, 1987), which provided a first comprehensive concept of global sustainable development. In this concept, stakeholders involved in agriculture are expected to adopt a systems perspective, which ranges from the management of the individual farm, to the interaction with the local ecosystem, and finally to all the communities that are affected by these farming systems both locally and globally. This systems perspective takes into account social responsibilities such as the needs of rural communities, consumer health and safety in present and in the future, as well as environmental responsibilities such as maintaining and enhancing the value of the natural resources as our common resource base (vanLoon, Patil, \& Hugar, 2005).

Switzerland decided to fully embrace this definition of sustainable agriculture in 1996 when Swiss citizens voted in favor of Article 104 of the Swiss constitution. It provides the legal basis for the promotion multifunctional agriculture (which is based on such a systems perspective) and can be seen as an explicit contract between farmers and society. A major task of the annual report of the Swiss Federal Office for Agriculture (BLW, 2007) is to monitor and analyze Swiss agricultural policy and examine whether the performance of 
Swiss agriculture is satisfactory from a sustainable development perspective. For that purpose, it has defined indicators that are to measure social, environmental, and economic sustainability. Even though these indicators are very much in accordance with the concept of the Brundtland report (1987), they seem to imply that it is merely the government's responsibility to ensure sustainable agriculture, whereas farmers are just asked to provide the necessary data that are needed to assess overall government performance. Farmers must comply with numerous standards and rules in return for access to numerous forms of government payments (direct payments, eco-payments). Such a system, however, is vulnerable to the principal-agent problem in the sense that the agent (the farmer) takes advantage of the situation of asymmetric information by passing on only the information that is required to get the payment from the principal (Aerni, 2006). As a result, farmers may not feel responsible themselves to manage their resources in a sustainable way and their farm management decisions may be guided by a complex calculation on how to maximize revenues from government payments rather than how to provide sustainable and innovative goods and services that add value to food choice and the environment. This principal-agent problem is not particular to Swiss agricultural policy but inherent in the Brundtland definition of sustainable development. The implicit assumption of the Brundtland report (1987) is that a sustainable future must be organized by wise social planners that seek the consent of rational and well-informed citizens to jointly implement a strategy that ensures a sustainable future. Yet, there is little discussion in their defensive view on how to activate the creative minds of farmers and researchers to think for themselves and find local solutions that may prove more effective and better for the environment than the solutions suggested by the social planners (the words 'entrepreneur' and 'innovation' do not appear in the index of the Brundtland report). In other words, the report tends to endorse a rational social-planning approach at the expense of the trial-and-error approach of innovative entrepreneurs that experiment with sustainable solutions on the ground. That does not mean that there is no role for government, but it may have to focus more on searching for best practices and rewarding innovation in the field of sustainable agriculture, and less on merely defining indicators of sustainable development and monitoring its implementation. This largely corresponds to the progressive approach as practiced by the New Zealand government.
Unlike Swiss agriculture, New Zealand agriculture literally went through a process of renewal during the process of unilateral liberalization in the 1980s, and the result was a more diversified and competitive agricultural sector, better food quality and vibrant rural communities that are actively involved in the political process of finding local solutions to emerging environmental problems. New Zealand nevertheless faces great challenges to make its agriculture more sustainable without undermining its global competitiveness. Yet its bottom-up approach in environmental policy as well as its significant public investments in technological innovation in agriculture make the country a pioneer in the pursuit of a new concept of sustainable agriculture that might not be in accordance with the social-planning model but is all the more effective in environmental management and less harmful to poor developing countries that face increasing non-tariff trade barriers in those countries that maintain a defensive view of sustainable agriculture. The bottom-up approach might also empower farmers and enable them to do more than just implement government and retailer directives and instead become fully integrated participants of the global knowledge economy.

Many Swiss stakeholders would argue that New Zealand is a different story and its policies are not applicable to the Swiss context. The fact that the prevailing New Zealand view is hardly represented by Swiss stakeholders seems to confirm this. However, Switzerland used to pursue the New Zealand approach in the 19th Century when it decided to set up agricultural research institutes to help farmers coping with increasing international competition in agricultural production (Brugger, 1956). At that time, the focus was on assisting farmers in solving agronomic problems with new technologies and services (developed by researchers in collaboration with the private sector and farmers) that make Swiss farming more productive and innovative. All the famous Swiss food products from cheese to chocolate have their roots in this period of early globalization. Today, the situation is different. Swiss agriculture is already quite capital-intensive, and its productivity high. Growth in sustainable agriculture must therefore happen through value-added products and the more efficient use of input rather than productivity increases. Since the use of new technologies is mainly associated with productivity increases, it is not seen as a contribution to sustainable agriculture in the Swiss context, and value-added agriculture is mainly associated with organic farming practices and the preservation of agro-biodiversity through the promotion and marketing of rare traditional food 
products and their protection through geographical indication. Yet, as the case of New Zealand demonstrates, new technologies such as agricultural biotechnology can be applied to increase food quality, enhance the value of traditional products, and reduce the environmental impact of agriculture. Switzerland might learn from this experience and redefine the role of agricultural research and technology in sustainable agriculture and thus return to the successful roots of Swiss agricultural policy in the 19th Century. That does not mean that the Swiss government should stop supporting the farmers but should support them in a different way. Rather than assuming the role of a nanny, it could assume the role of a coach that assists farmers in their efforts to become innovation-driven entrepreneurs. It could also financially encourage Swiss researchers to collaborate more closely with farmers and the private sector in the development of sustainable technological innovation in agriculture. This would constitute a valuable counter-weight to the increasing power of retailers. However, this is unlikely to happen as long as this alternative view of sustainable agriculture is not represented in the public debate in Switzerland. A change of attitude by a single influential stakeholder in the debate may change the entire public debate. In New Zealand, it was the Federated Farmers that decided to do so in the 1980s when they created the critical political support for agricultural reform because they worried about their dependence on government support and the subsequent loss of decision-making power. In Switzerland, the Swiss Farmer Association (Bauernverband), which turned out to be the central player in the Swiss debate, may also decide to change from a defensive to a more progressive strategy and thus facilitate change in agricultural policy and a redefinition of sustainable agriculture. This would make Swiss agriculture more compatible with the spirit of the WTO Agreement on Agriculture and, at the same time, allow the government to continue to support selected marginal small-scale farmers in the mountain regions that provide a genuine public service (through greenbox measures), assist its more competitive farmers in the lower regions with payments that are linked to performance (measured not just in terms of compliance with pre-determined 'good agricultural practices,' but innovation and entrepreneurship), and invest in research and technology that is of relevance to the farmers' competitiveness and sustainability. Ultimately, only such a new approach may genuinely empower Swiss farmers as entrepreneurs and ensure the long-term sustainability of Swiss agriculture, because the conventional concept of sustainable agriculture may no longer be sustainable.

\section{References}

Aerni, P. (2006). The principal-agent problem in development assistance and its negative impact on entrepreneurship: Time for new approaches. ATDF (African Technology Development Forum) Journal, 3(2), 27-33.

Aerni, P. (2008). A new approach to deal with the global food crisis. ATDF Journal, 5(1/2), 16-32.

Aerni, P. (2009). What is sustainable agriculture? Empirical evidence of diverging views in Switzerland and New Zealand. Ecological Economics, 68(6), 1872-1882.

Aerni, P., \& Bernauer, T. (2006). Stakeholder attitudes towards GMOs in the Philippines, Mexico and South Africa: The issue of public trust. World Development, 34(3), 557-575.

Aerni, P., Rae, A., \& Lehmann, B. (2009). Nostalgia vs. pragmatism? How attitudes and interests shape the term sustainable agriculture in Switzerland and New Zealand. Food Policy, 34(2), 227-235.

Altieri, M. (1995). Agroecology: The science of sustainable agriculture. New York: Westview Press.

Bail, C., Falkner, R., \& Marquard, H. (Eds.). (2002). The Cartagena Protocol on Biosafety-Reconciling trade in biotechnology with environment \& development? London: Earthscan.

Beckerman, W. (2003). A poverty of reason: Sustainable development and economic growth. Oakland, CA: The Independent Institute.

Binswanger, M., \& Jochen, A. (2005). Entkoppelung von Wirtschaftswachstum und Umweltbelastung im Klimaschutz [Decoupling economic growth and environmental climate protection]. Die Volkswirtschaft, 7/8, 18-27.

Brugger, H. (1956). Die Schweizerische Landwirtschaft in der ersten Hälfte des 19 Jahrhunderts [Swiss agriculture in the first half of the 19th Century]. Frauenfeld, Switzerland: Huber Verlag.

Brundtland, G. (1987). Our common future: The World Commission on Environment and Development. Oxford: Oxford University Press.

Buchanan, J.M., \& Tullock, G. (1962). The calculus of consent: Logical foundations of constitutional democracy. Ann Arbor: University of Michigan.

Bundesamt für Landwirtschaft [Federal Office for Agriculture] (BLW). (2007). Agrarbericht 2007 [Agricultural report 2007]. Bern, Switzerland: Author.

Campbell, H. (2005). The rise and rise of EurepGAP: European (re)invention of colonial foods relations? International Journal of Sociology of Food and Agriculture, 13, 1-19.

Carrington, P.J., Scott, J., \& Wasserman, S. (2005). Models and methods in social network analysis. New York: Cambridge University Press.

Chamberlin, B. (1996). Farming and subsidies: Debunking the myths. Wellington, NZ: Euroa Farms Ltd. 
Cooney, R., \& Dickson, B. (2007). Biodiversity and the precautionary principle. London: Earthscan.

European Commission. (2000). Communication on the precautionary principle. Brussels: Author. Available on the World Wide Web: http://ec.europa.eu/environment/docum/ 20001_en.htm.

Fold, N., \& Pritchard, B. (2005). Cross-continental food chains. New York: Routledge.

Francioni, F. (2001). Environment human rights and international trade. New York: Oxford University Press.

Freidberg, S. (2007). Supermarkets and imperial knowledge. Cultural Geographies, 14(3), 321-342.

Dolan, C. (2004). Benevolent intent? The development encounter in Kenya's horticulture industry. Journal of Asian and African Studies, 40, 411-437.

Drayton, R.H. (2000). Nature's government: Science, imperial Britain, and the 'improvement' of the world. New Haven, CT: Yale University Press.

Häberli, C. (2008, July). Market access in Switzerland and in the European Union for agricultural products from least developed countries (NCCR Trade Regulation Working Paper 2008/5). Bern, Switzerland: World Trade Institute, University of Bern.

International Assessment of Agricultural Science and Technology for Development (IAASTD). (2008). Agriculture at a crossroads. Washington, DC: Island Press. Available on the World Wide Web: http://www.agassessment.org/.

Kasperson, R.E., Renn, O., Slovic, P., Brown, H.S., Emel, J., Goble, R., et al. (1988). The social amplification of risk: A conceptual framework. Risk Analysis, 8(2), 177-187.

Kingsbury, N. (2009). Hybrid: The history \& science of plant breeding. Chicago: University of Chicago Press.

Koordinationsstelle Biodiversitäts-Monitoring [Biodiversity Monitoring Coordination Unit]. (2009). Zustand der Biodiversität in der Schweiz. Ergebnisse des Biodiversitätsmonitorings (BDM) im Überblick [State of biodiversity in Switzerland. Results of the Biodiversity Monitoring (DBM) at a glance] (Umwelt-Zustand Nr. [Environmental Condition No.] 0911). Bern, Switzerland: Bundesamt für Umwelt (BAFU) [Federal Office for Environment]. Available on the World Wide Web: http://www.biodiversitymonitoring.ch/english/aktuell/synthese.php.

Laumann, E.O., \& Knoke, D. (1987). The organizational state: Social choice in national policy domains. Madison: The University of Wisconsin Press.

Luhmann, N. (1993). Risk: As sociological theory. Hawthorne, NY: Aldine de Gruyter.

Ministry of Agriculture and Forestry (MAF). (2003). Agriculture and forestry in New Zealand: An overview. Wellington, New Zealand: Author. Available on the World Wide Web: http:// www.maf.govt.nz/mafnet/rural-nz/overview/ nzoverview004.htm.
NZZ Online (Neue Zürcher Zeitung). (2009, June 9). Auf der Suche nach dem Bauernsterben: Schleppender Strukturwandel in der Landwirtschaft [In search of the Polish farming: Sluggish structural change in agriculture]. Zurich, Switzerland: Author. Available on the World Wide Web: http:// www.nzz.ch/nachrichten/schweiz/ bauernsterben_1.2702869.html.

Nordhaus, T., \& Shellenberger, M. (2007). Break through: From the death of environmentalism to the politics of possibility. Boston. MA: Houghton Mifflin Company.

Paarlberg, R. (2008). Starved for science. Cambridge, MA: Harvard University Press.

Parliamentary Commissioner of the Environment (PCE). (2004). Growing for good: Intensive farming, sustainability and New Zealand's environment. Wellington, New Zealand: Author.

Peters, G., \& Pierre, J. (2003). Handbook of public administration. New York: Sage Publications.

Power, M. (1997). The audit explosion. Oxford: Clarendon Press.

Raffensberger, C., \& Tickner, J. (1999). Protecting public health and the environment: Implementing the precautionary principle. Washington, DC: Island Press.

Rentsch, H. (2006). Der befreite Bauer: Anstösse für den agrarpolitischen Richtungswechsel [The freed farmer: Impetus for the agricultural policy direction]. Zurich, Switzerland: Verlag Neue Zürcher Zeitung and Avenir Suisse.

Romer, P. (1994). New goods, old theory and the welfare costs of trade restrictions. Journal of Development Economics, 43(1), 5-38.

Ronald, P., \& Adamchak, R.W. (2008). Tomorrow's table. New York: Oxford University Press.

Schweizerischer Bundesrat [Swiss Federal Council]. (2006). Botschaft zur Weiterentwicklung der Agrarpolitik 2011 [Message to the development of agricultural policy in 2011]. Bern, Switzerland: Author.

Sjöberg, L. (2003). Attitudes and risk perceptions of stakeholders in a nuclear waste siting issue. Risk Analysis, 23(4), 739-749.

Sunstein, C.R. (2005). Laws of fear: Beyond the precautionary principle. New York: Cambridge University Press.

Van Huylenbroeck, G., \& Durand, G. (2003). Multifunctional agriculture: A new paradigm for European agriculture and rural development. Burlington, VT: Ashgate.

vanLoon, G.W., Patil, S.G., \& Hugar, L.B. (2005). Agricultural sustainability: Strategies for assessment. New York: Sage Publications.

Von Hippel, E. (2006). Democratizing innovation. Cambridge, MA: MIT Press.

Vives, A. (2001). The role of multilateral development institutions in fostering corporate social responsibility. Development, 47(3), 45-52. 